\title{
Fenomena Kompetisi Video Dance melalui Instagram (Studi Fenomenologi pada Komunitas Dancer di Surabaya)
}

\author{
Dance Video Competition Phenomenon on Instagram \\ (A Phenomenology Study on Dancer Communities in Surabaya)
}

\author{
Lu'lu Mutia \& Sylvie Nurfebiaraning \\ Universitas Telkom, Bandung, Jawa Barat, Indonesia \\ lulumutiaa@gmail.com
}

Naskah diterima tanggal 11/03/2019, direvisi akhir tanggal 22/04/2019, disetujui tanggal 30/04/2019

\begin{abstract}
Abstrak
Instagram merupakan sebuah aplikasi yang digunakan oleh semua orang agar terhubung dengan pengguna lain dan dapat dimanfaatkan untuk mengirimkan informasi dalam bentuk gambar atau foto, video, dan berbagi (share). Instagram digunakan oleh Telkomsel Area Jabotabek Jabar untuk membuat konten kontes atau kompetisi yang berlangsung saat Asian Games 2018, yaitu kompetisi video dance \#YoAyoChallenge. Kompetisi online melalui Instagram ini diikuti oleh anggota Komunitas Valkyrie dan anggota Komunitas Fresh DC dari Surabaya serta berhasil menjadi pemenang harapan kedua. Tujuan penelitian adalah untuk mengetahui motif, interaksi, makna dari keikutsertaan individu-individu yang berkolaborasi dan membentuk kelompok. Penelitian ini menggunakan metode kualitatif dengan pendekatan fenomenologi Alfred Schutz dan paradigma konstruktivis. Teknik pemilihan informan yakni purposive sampling dengan informan utama dan informan pendukung sejumlah empat orang. Hasil penelitian ini adalah, pertama adanya because motives (motif sebab) yaitu motif kegiatan, motif afiliasi, motif kompetensi dan ada in-order-motives (motif tujuan) yaitu motif berprestasi dan motif berkuasa. Kedua, interaksi antar anggota kelompok melalui komunikasi kelompok dengan melaksanakan fungsi tugas dan fungsi pemeliharaan. Ketiga, makna terhadap keikusertaan di kompetisi adalah memperkenalkan diri, memperkenalkan komunitas, menguji kemampuan diri, mendapatkan perhatian, mendapatkan pengakuan, dan mengekspresikan perasaan.
\end{abstract}

Kata Kunci: instagram, interaksi, kompetisi online, makna, motif

\begin{abstract}
Instagram is an application used by everyone to connect with another users and can be used to send information in the form of images or photos, videos, and share. Instagram is used by Telkomsel Jabotabek Jabar Area to create contest or competition content that was held during Asian Games 2018, which was \#YoAyoChallenge dance video competition. This online competition on Instagram was participated by Valkyrie Community and Fresh DC Community members from Surabaya who succeeded to be the fifth winner of the competition. This research aims to understand motive, interaction, and meaning of the participation of those individuals who collaborated into a group. This qualitative research uses Alfred Schutz's phenomenology approach and constructivism paradigm. The sampling was done by purposive sampling to choose four key informants and supporting informants. The result of this research shows that there is because motives such as activity motive, affiliation motive, competency motive, and in order to motives such as achievement motive and ruling motive. Second, interaction between the group members occurred through group communication by carrying out task function and maintenance function. Third, the meaning of the participation in this competition is to introduce their selves, to introduce their communities, to test their ability, to gain attention, to gain acknowledgement, and to express their feelings.
\end{abstract}

Keywords: instagram, interaction, meaning, motive, online competition. 


\section{PENDAHULUAN}

Instagram adalah aplikasi yang digunakan oleh semua orang untuk mengirimkan informasi dalam bentuk gambar atau foto, video dan berbagi (share) ke jejaring sosial yang lain. Instagram disebut media sosial yang dinamis karena selalu menciptakan fitur-fitur terbaru dan dapat memenuhi kebutuhan setiap penggunanya. Selain itu, Instagram dapat merepresentasikan individu atau sekelompok orang, berinteraksi, berkomunikasi bersama pengguna lain dan hal ini dapat terwujud apabila didukung dengan konten interaktif untuk membangun hubungan antar pengguna. Jenis-jenis konten di Instagram yaitu foto, video, infografis, stories, kontes, konten influencer, usergenerated content.

Akan tetapi, dalam penelitian ini akan membahas jenis konten kontes atau konten kompetisi yang diselenggarakan Telkomsel Area Jabotabek Jabar saat berlangsungnya Asian Games 2018. Kompetisi atau kontes di Instagram yang memiliki tujuan dan konsep yang sama seperti \#YoAyoChallenge adalah kompetisi video dari PT Bank Negara Indonesia (BNI) sebagai Official Prestige Partner di Asian Games 2018 serta kompetisinya bernama \#KamiBisaIndonesiaJuara video competition. Menurut peneliti, kompetisi video dance \#YoAyoChallenge sebagai bagian dari fokus peneliti lebih unggul dibandingkan dengan kompetisi \#KamiBisaIndonesiaJuara video competition karena konsep dan tema kompetisi yang detail, syarat dan ketentuan yang fokus serta hadiahnya yang dapat memenuhi kebutuhan sekunder setiap individu seperti handphone, motor, kamera, jam tangan.

Berdasarkan observasi peneliti dari 30 Agustus 2018-20 November 2018 di Instagram bahwa kompetisi video dance \#YoAyoChallenge mendapatkan perhatian maksimal karena penggunaan hastag dari \#YoAyoChallenge mencapai 3,239 postingan dan hastag \#KamiBisaIndonesiaJuara hanya mencapai 231 postingan. Dengan begitu, kompetisi video dance \#YoAyoChallenge menjadi bagian dari fokus penelitian peneliti.

Peserta kompetisi video dance \#YoAyoChallenge adalah seniman aktif di komunitas dancer hingga influencer yang senang menari. Akan tetapi, peneliti memilih anggota komunitas dancer dari Surabaya yang menjadi pemenang harapan kedua yaitu Yuni Halim dan Yustina Okvitarani sebagai anggota Komunitas Valkyrie serta Arthur dan Buyung Eliyasa sebagai anggota Komunitas Fresh DC. Kedua komunitas ini berkolaborasi dan membentuk kelompok yang memiliki tujuan sama dalam keikutsertaannya di kompetisi video dance \#YoAyoChallenge. Melakukan kolaborasi karena kesamaan visi yang dimiliki oleh komunitas yaitu ingin menghasilkan karya dalam dunia dance dan mengubah pandangan negatif masyarakat terhadap dance dengan aktif mengikuti kompetisi. Kompetisi yang diikuti pada masa lalu merupakan usaha untuk menarik perhatian publik agar menjadi pusat perhatian pada suatu waktu.

Komunikasi kelompok terjadi saat proses pembuatan video dance \#YoAyoChallenge dan mereka saling berinteraksi untuk menjalankan perannya sebagai anggota kelompok. Menurut Michael Burgoon dan Michael Ruffner dalam buku yang berjudul "Teori Komunikasi" oleh (Daryanto \& Rahardjo, 2015:84-85) yang menjelaskan pengertian dari komunikasi kelompok. Komunikasi kelompok adalah interaksi tatap muka yang terjalin antara tiga atau lebih individu untuk memperoleh maksud dan tujuan yang dikehendaki seperti pemeliharaan diri, pemecahan masalah, berbagi informasi dengan anggota kelompok lainnya. Empat elemen yang harus dipenuhi 
dalam komunikasi kelompok yaitu, interaksi tatap muka, jumlah partisipan, memiliki maksud dan tujuan yang dikehendaki, serta kemampuan anggota untuk menumbuhkan karakteristik pribadi anggota lainnya. Kelompok ini sudah memenuhi karakteristik dari kelompok dan komunikasi kelompok.

Sebelum membuat kelompok, terdapat alasan yang mendorong Yuni, Yustina, Arthur dan Buyung mengikuti kompetisi video dance \#YoAyoChallenge. Dorongan atau motif ini menjadi penggerak dalam diri masing-masing individu dan proses kesadaran yang menyebabkan adanya perilaku tersebut. Dorongan ini disebabkan oleh faktor personal yang sudah terikat pada suatu tujuan. Dorongan atau motif ini dapat berorientasi pada masa lalu yang menjadi sebab dan masa akan datang yang menjadi tujuan ia berpartisipasi karena semua tingkah laku manusia mempunyai motif (Ginitasasi, 2015). Setelah adanya dorongan sebagai dasar keikutsertaannya, maka akan ada makna yang dimiliki setiap individu setelah kompetisi sudah dilaksanakan untuk menginterpretasikan kegiatan tersebut dari proses internal di dalam diri masing-masing.

Sebenarnya fokus penelitian motif (because of motive and in-order to motive) dan interaksi (komunikasi kelompok) telah banyak di teliti meskipun dalam tema yang berbeda yaitu dalam tema plagiarism (Miranti, 2015), pendidikan (Guntaradewa, 2011), fenomena sosial (Ginitasasi, 2015; Sari, 2018; UTAMI, 2018), branding (Astiani, 2017; Ramadhanti, 2016) dan tema lainnya. Tetapi penelitian ini akan lebih memfokuskan pada keikutsertaan anggota Komunitas Valkyrie dan anggota Komunitas Fresh DC yang berkolaborasi di kompetisi video dance \#YoAyoChallenge. Maka judul penelitian ini adalah "Fenomena Kompetisi Video Dance Melalui Instagram (Studi Fenomenologi pada Komunitas Dancer di
Surabaya)" akan melakukan penelitian lebih mendalam untuk memahami motif (because motives dan in order motives), interaksi dan makna dengan tradisi kedua dalam ilmu komunikasi yaitu fenomenologi, perspektif Alfred Schutz sebagai tokoh pertama yang membawa tradisi fenomenologi pada penelitian sosial praktis.

Peneliti akan mendeskripsikan pengalaman sadar Yuni, Yustina, Arthur dan Buyung ketika memilih dan ikut serta di kompetisi video dance \#YoAyoChallenge. Mereka juga akan secara aktif menginterpretasikan pengalaman personal secara langsung. Hal in sesuai dengan pernyataan dari Stanley Deetz dalam buku yang berjudul "Teori Komunikasi (Komunikator, Pesan, Percakapan, dan Hubungan (interpersonal)" oleh (Morrisan, 2017:31) yang menjelaskan bahwa fenomenologi menjadikan pengalaman sebenarnya sebagai data utama dalam memahami realitas dan apa yang diketahui oleh informan adalah apa yang dialaminya.

\section{METODE PENELITIAN}

Pada penelitian ini, peneliti menggunakan paradigma konstruktivisme (paradigma alternative). Paradigma ini yang meneguhkan asumsi bahwa individuindividu selalu berusaha memahami dunia di mana mereka hidup dan bekerja. Mereka mengembangkan makna-makna subjektif atas pengalaman mereka, makna-makna yang diarahkan pada objek-objek atau bendabenda tertentu. Makna-makna ini cukup beragam sehingga peneliti dituntut untuk lebih mencari kompleksitas pandanganpandangan ketimbang mempersempit makna-makna menjadi sejumlah kategori dan gagasan. Peneliti akan berusaha mengandalkan sebanyak mungkin pandangan partisipan tentang situasi yang tengah diteliti 
melalui pertanyaan-pertanyaan. Tujuan utama menggunakan paradigma ini adalah berusaha mengungkapkan kebenaran makna yang terselubung dari anggota komunitas Valkyrie dan anggota Komunitas Fresh DC yang ikut serta di kompetisi video dance \#YoAyoChallenge melalui Instagram dengan pengalaman pribadinya. Peneliti juga akan mengembangkan suatu teori atau pola makna tertentu secara induktif (khusus-umum).

Dalam penelitian ini, peneliti menggunakan metode penelitian kualitatif dan penelitian kualitatifyang akan memahami fenomena apa yang dialami subjek penelitian. Penelitian juga menggunakan pendekatan fenomenologi dan penelitian dilakukan untuk mengetahui motif, interaksi (komunikasi kelompok) dan makna setelah mengikuti kompetisi video dance melalui Instagram sebagai kompetisi online yang berlangsung saat Asian Games 2018. Objek penelitian adalah permasalahan yang akan diteliti dan menjadi titik atau pusat perhatian dari suatu penelitian. Objek penelitian ini adalah motif, interaksi, dan makna anggota Komunitas Valkyrie dan anggota Komunitas Fresh DC yang ikut serta di kompetisi video dance melalui Instagram.

Dalam penelitian ini, unit analisisnya berupa manusia serta peneliti akan memfokuskan penelitian pada anggota Komunitas Valkyrie dan anggota Komunitas Fresh DC yang ikut serta di kompetisi video dance \#YoAyoChallenge sebagai individu maupun kelompok. Sedangkan teknik pengumpulan data yang dipakai menggunakan tiga metode sesuai dengan prosedur penelitian kualitatif dan pendekatan sescara langsung yaitu, pengamatan (observasi), wawancara mendalam, dan metode dokumentasi. Dengan Teknik analisis data yang mengacu pada pada metode fenomenologi dan berdasarkan metode dari Moustakas (1994).

\section{HASIL PENELITIAN DAN PEMBAHASAN}

\subsection{Hasil}

Menurut para pengikut filsafat fenomenologi, fenomena adalah "apa yang menampakkan diri dengan dirinya sendiri”, apa yang menampakkan diri seperti apa adanya, apa yang dijelas dihadapan kita (Farid, 2018: 23-27). Kompetisi video dance \#YoAyoChallenge melalui Instagram disebut sebagai kompetisi online yang diikuti oleh Yuni Halim dan Yustina Okvitarani sebagai anggota Komunitas Valkyrie serta Arthur dan Buyung sebagai anggota Komunitas Fresh DC yang saling berkolaborasi untuk membentuk suatu kelompok. Keikutsertaan individu pada kompetisi ini atas dasar dorongan dalam diri. Motif adalah penggerak, dorongan, hasrat dan alasan yang terdapat dalam diri manusia dan menyebabkan ia berbuat sesuatu. Menurut Hambali, motif-motif manusia dapat bekerja secara sadar dan tidak sadar bagi diri manusia. Motif merupakan suatu konstruksi yang potensial dan laten, yang dibentuk oleh pengalaman, yang secara relative dapat bertahan meskipun kemungkinan berubah masih ada, dan berfungsi menggerakkan untuk mengarahkan perilaku ke tujuan tertentu (Hambali \& Jaenudin, 2015:143). Motif yang akan ditelaah dalam penelitian ini adalah dorongan akan kegiatan, dorongan akan berprestasi, dorongan akan afiliasi, dorongan kompetensi dan dorongan akan berkuasa.

Interaksi yang ingin dianalisis oleh peneliti yaitu komunikasi kelompok dan fungsi peran dalam suatu kelompok saat proses pembuatan video dance \#YoAyoChallenge. Komunikasi kelompok mempunyai batasan seperti adanya interaksi tatap muka dari tiga atau lebih individu guna memperoleh maksud dan tujuan yang dikehendaki (Daryanto \& Rahardjo, 2015:8488). Anggota kelompok ini sudah memenuhi 
kriteria dan menunjukkan adanya komunikasi kelompok yang terjadi saat proses pembuatan video dance \#YoAyoChallenge. Selain itu, mereka melaksanakan fungsi peran dalam suatu kelompok yaitu fungsi tugas dan fungsi pemeliharaan. Fungsi tugas meliputi memberi dan mendapatkan informasi, memberi pendapat, memberi aturan. Fungsi pemeliharaan meliputi pendorong partisipasi, penyelaras, penurun ketegangan, dan penengah persoalan pribadi.

Makna adalah hasil interaksi atau hasil komunikasi kita dengan orang lain. Setiap individu menggunakan makna untuk menginterpretasikan peristiwa di sekitar dan interpretasi merupakan proses internal dalam diri kita (Morrisan, 2017:145-147). Peneliti melakukan analisis terkait makna dari masing-masing anggota kelompok setelah mengikuti kompetisi video dance \#YoAyoChallenge. Asumsi yang digunakan adalah asumsi dari Herbert Blumer yaitu manusia bertindak berdasarkan makna yang diberikan kepada dirinya, makna diciptakan melalui proses interaksi sosial dengan sesama dan makna dimodifikasi melalui interpretasi indvidu tersebut (Ahmadi, 2008:309-310). Selain itu, menggunakan tiga konsep penting oleh George Herbert Mead mengenai self (diri), mind (pemikiran), and society (masyarakat) (Morrisan, 2017:7476). Makna dari kompetisi online ini yaitu, memperkenalkan diri, memperkenalkan komunitas, menguji kemampuan diri, mendapatkan perhatian, mendapatkan pengakuan dan mengekspresikan perasaan.

\subsection{Pembahasan}

\section{Motif}

Motif sebagai dorongan yang dimiliki setiap individu dan mempengaruhi perilakunya atau bertindak. Motif kegiatan adalah ingin belajar membuat koreografi, menghibur penonton, mengurangi tingkat stres. Motif berprestasi adalah ingin menciptakan sesuatu dengan cara yang baru dan kreatif, mempunyai keinginan untuk berprestasi lebih baik, mempunyai standar prestasi dan berpatokan pada standar tersebut. Motif afiliasi adalah senang bergaul dengan orang lain dan melakukan tugas lebih baik saat bekerja dalam kelompok, selalu merasa senang ketika berada di tengah keramaian karena menikmati persahabatan, selalu berusaha memberikan prestasi terbaik untuk komunitasnya. Motif kompetensi adalah ingin membuktikan bahwa ia adalah individu yang mampu mengatasi persoalan kehidupan apapun karena mereka tidak mendapatkan dukungan dari orang sekitar, menghilangkan rasa tidak percaya pada kemampuan sendiri, ketidakmampuan tampil di depan umum dan mulai berlatih di kompetisi online. Motif berkuasa adalah ingin memiliki pengaruh terhadap orang lain dan ingin membuat orang lain terkesan dengan apa yang dimilikinya. Berdasarkan teori Schutz mengenai dua fase historis yaitu untuk menunjukkan fase motif di masa lalu (because motive) dan untuk menunjukkan fase motif di masa akan datang (in order to motive) (Kuswarno, 2009:194). Dengan begitu, yang menjadi golongan motif di masa lalu (because motive) seperti motif kegiatan, motifafiliasi, dan motif kompetensi. Sedangkan, yang menjadi golongan motif di masa akan datang (in-order to motive) seperti motif berprestasi dan motif berkuasa.

\section{Interaksi}

Interaksi dalam penelitian yang berjudul "Fenomenologi Kompetisi Video Dance Melalui Instagram (Studi Fenomenologi pada Komunitas Dancer di Surabaya)" ini mengacu pada satu diantara empat tipe ideal yaitu the insider (orang dalam) dari konsep tipikasi oleh Schutz dan berkaitan dengan interaksi sosial antar pribadi dalam fenomenologi. Sehingga, peneliti akan menerima informasi terkait kelompok melalui individu-individu yang 
sudah mengalami hal tersebut.

$$
\text { Berdasarkan hasil penelitian }
$$

mengenai interaksi antar anggota kelompok yang melaksanakan fungsi peran dalam suatu kelompok. Memberi informasi adalah tugas dari Buyung dan mendapatkan informasi yaitu Yuni, Yustina, Arthur. Pendorong partisipasi adalah cara individu mempengaruhi anggota kelompok lainnya seperti kesamaan visi dan misi serta ada anggota kelompok yang menyakinkan anggota lainnya untuk ikut serta dengan waktu yang terbatas. Memberi pendapat adalah tugas semua anggota kelompok yaitu memberi ide terkait gerakan tari atau semua anggota wajib berperan sebagai koreografer. Memberi aturan yaitu dengan membuat jadwal latihan rutin, tempat latihan dan aturan lainnya terkait pembuatan video dance. Penyelaras yaitu dengan melakukan koordinasi terkait unggah video dance \#YoAyoChallenge melalui Instagram. Penurun ketegangan ini berarti selalu mencari solusi saat ada momen perbedaan pendapat. Penengah persoalan pribadi yang terjadi saat ada anggota kelompok yang mempunyai masalah pribadi dan anggota kelompok lainnya berusaha untuk membantu menyelesaikan persoalan pribadi agar kreativitas individu tersebut tidak menurun.

Peran merupakan pola-pola perilaku yang diharapkan dari setiap anggota kelompok. Ada dua fungsi peran dalam suatu kelompok (tabel 1) yaitu fungsi tugas dan fungsi pemeliharaan (Daryanto \& Rahardjo, 2015:87-88).

Tabel 1. Fungsi Tugas dan Fungsi Pemeliharaan

\begin{tabular}{ll}
\hline Fungsi Tugas & Fungsi Pemeliharaan \\
\hline Pemberi informasi & Pendorong partisipasi \\
Pemberi pendapat & Penyelaras \\
Pencari informasi & Penurunan ketegangan \\
Pemberi aturan & Penengah persoalan pribadi \\
\hline
\end{tabular}

(Daryanto \& Rahardjo, 2015:87-88)

Ada dua tanda kelompok secara psikologis yang di mana anggota-anggota kelompok ini saling terikat atau ada sense of belonging dan dapat dibuktikan melalui pembagian fungsi peran dalam suatu kelompok. Selain itu, nasib-nasib anggota kelompok ini saling bergantung karena hasil dari setiap anggota akan mempengaruhi hasil yang lain misalnya saat anggota memberi pendapat terkait pola gerakan yang akan menentukan hasil akhir dari video dance untuk diikuti pada kompetisi video dance \#YoAyoChallenge (Riswandi, 2009:120).

Selain itu, faktor-faktor personal yang mempengaruhi kelompok ini adalah tindak komunikasi melalui pertukaran informasi. Masing-masing anggota kelompok dapat menyampaikan atau menerima informasi secara verbal maupun non-verbal. Selain itu, ada peranan yang dimainkan oleh anggota kelompok seperti penjelasan di atas mengenai dua fungsi peran yaitu fungsi tugas dan fungsi pemeliharaan. Peran ini akan membantu penyelesaian tugas kelompok, memelihara hubungan emosional yang baik antar anggota (Riswandi, 2009:127-128). Menurut peneliti, kelompok yang mengikuti kompetisi video dance \#YoAyoChallenge ini merupakan kelompok primer karena ada hubungan emosional, personal dan saling akrab karena seperti hubungan teman sepermainan. Hal ini dapat dibuktikan dengan komunikasi antar anggota yang menekankan aspek hubungan daripada isi seperti ada yang melaksanakan fungsi tugas yaitu penurunan ketegangan dan penengah persoalan pribadi 
untuk memelihara hubungan baik (Riswandi, 2009:120-121).

\section{Makna}

Berdasarkan hasil penelitian mengenai makna keikutsertaan di kompetisi video dance \#YoAyoChallenge adalah memperkenalkan diri kepada khalayak dan menunjukkan kemampuan diri, memperkenalkan komunitas, menguji kemampuan diri dalam menciptakan ide koreografi dan menjadi bahan evaluasi di masa yang akan datang, mendapatkan perhatian lebih mudah dan cepat, mendapatkan pengakuan dari orang sekitar, serta mengekspresikan perasaan seperti rasa bangga dan rasa percaya diri ketika ikut kompetisi online.

Makna adalah hasil komunikasi yang penting karena makna sebagai hasil interaksi kita dengan orang lain. Setiap individu menggunakan makna untuk menginterpretasikan peristiwa di sekitar dan interpretasi merupakan proses internal di dalam diri kita (Morrisan, 2017:145-147). Interaksi simbolik memberikan perhatian pada cara-cara bagaimana manusia bersatu (konvergensi) dalam menentukan makna. Dalam penelitian ini menggunakan dua asumsi yaitu asumsi George Herbert Mead yaitu pikiran, diri, masyarakat dan Herbert Blumer yaitu manusia bertindak terhadap manusia lain atas dasar makna yang diberikan oleh orang lain, makna diciptakan dalam interaksi antarmanusia, serta makna dimodifikasi melalui proses interpretif (West \& Turner, 2008:98-108).

Memperkenalkan diri, memperkenalkan komunitas, menguji kemampuan diri, mengekspresikan perasaan, menggunakan satu diantara asumsi dari Herbert Blumer yaitu makna dimodifikasi melalui proses interpretif dan individu tersebut memiliki potensi untuk mengembangkan dirinya melalui modifikasi makna. Sedangkan mendapatkan perhatian ini menggunakan satu diantara asumsi dari Herbert Blumer yaitu manusia bertindak atas segala sesuatu berdasarkan makna yang diberikan orang lain kepada mereka. Mendapatkan pengakuan menggunakan satu diantara tiga konsep penting dari George Herbert Mead mengenai diri (self) untuk mengambil peran dengan membayangkan bagaimana kita dilihat oleh orang lain.

\section{KESIMPULAN}

Berikut hasil penelitian yang berjudul "Fenomena Kompetisi Video Dance Melalui Instagram (Studi Fenomenologi pada Komunitas Dancer di Surabaya) dapat diketahui bahwa Motif yang melatar belakangi keikutsertaan anggota Komunitas Valkyrie dan anggota Komunitas Fresh DC di Surabaya pada kompetisi video dance \#YoAyoChallenge dari Telkomsel Area Jabotabek Jabar yang berlangsung saat Asian Games 2018 (1) Because motive (motif sebab) yaitu adanya dorongan akan kegiatan, dorongan akan afiliasi, dorongan akan kompetensi dan (2) In-Order to Motive (motif karena) yaitu adanya dorongan akan berprestasi dan dorongan akan berkuasa.

Selain itu, hasil lain dari penelitian ini terlihat adanya interaksi dalam komunikasi kelompok saat proses pembuatan video dance \#YoAyoChallenge, dengan melaksanakan fungsi peran yaitu fungsi tugas dan fungsi pemeliharaan. Sedangkan untuk makna yang dibangun oleh anggota kelompok di kompetisi video dance \#YoAyoChallenge adalah memperkenalkan diri, memperkenalkan komunitas, menguji kemampuan diri, mendapatkan perhatian, mendapatkan pengakuan, dan mengekspresikan perasaan. Makna ini berkaitan dengan asumsi dari George Herbert Mead dan Herbert Blumer dari teori interaksi simbolik. 


\section{DAFTAR RUJUKAN}

Ahmadi, D. (2008). Interaksi Simbolik: Suatu Pengantar. Mediator: Jurnal Komunikasi, 9(2), 301-316. https://doi. org/10.29313/MEDIATOR.V9I2.1115

Astiani, M. C. (2017). Instagram sebagai Alat Presentasi Diri Mahasiswa. Universitas Islam Negeri Sunan Kalijaga Yogyakarta.

Daryanto, \& Rahardjo, M. (2015). Teori Komunikasi. Yogyakarta: Gava Media.

Ginitasasi, R. (2015). MOTIF SOSIAL. Bandung.

Guntaradewa, O. Y. (2011). Motif Tindakan Mahasiswa dalam Gerakan Mahasiswa Mengajar. Surabaya.

Hafiz, Muhammad Perkasa Al. (2016, Agustus). Instagram (Korelasi Antara Bisnis dan Konten). Marketeers, The Ultimate Guide To Social Media Marketing, 50-51.

Hambali, A., \& Jaenudin, U. (2013). Psikologi Kepribadian Lanjutan Studi Atas Teori Dan Tokoh Psikologi Kepribadian. Bandung: Pustaka Setia.

Kuswarno, E. (2009). Fenomenologi (Konsepsi, Pedoman, dan Contoh Penelitian). Bandung: Widya Padjajaran.

Miranti, V. A. (2015). Internet Plagiarism di Kalangan Mahasiswa (Studi Fenomenologi Tentang Motif Internet Plagiarism Di Kalangan Mahasiswa Ilmu Informasi dan Perpustakaan Universitas Airlangga). Surabaya.

Morrisan. (2017). Teori Komunikasi Individu Hingga Masa. Jakarta: Prenada Media.

Moustakas, C. E. (1994). Phenomenological research methods. Thousand Oaks, CA, US: Sage Publications, Inc.

Ramadhanti, T. R. (2016). Fenomena Pemanfaatan Instagram sebagai Media Personal Branding. Universitas Dipenogoro.

Riswandi. (2009). Ilmu Komunikasi. Jakarta: Graha Ilmu.

Sari, R. F. (2018). MotifDan Makna Anggota Komunitas Odoj Bandar Lampung dalam Tradisi Fenomenologialfred Schutz. Universitas Lampung.

UTAMI, M. R. (2018). Fenomena Penggunaan Instagram Stories (Studi Fenomenologi pada Mahasiswi di Bandung). Universitas Telkom.

West, R., \& Turner, L. H. (2008). Pengantar Teori Komunikasi: Analisis dan Aplikasi 2. Jakarta: Salemba Humanika. 